\title{
Studies on In Vivo Formation of Nitroso Compounds (VI)
}

\author{
In Vitro and In Vivo Formation of Dimethylnitrosamine \\ by Bacteria Isolated from Human Saliva
}

(Received August 30, 1975)

\author{
Hajimu Ishiwata*1, Akio TANIMURA*1 and Morizo Ishidate*2 \\ (*1 National Institute of Hygienic Sciences: 18-1, Kamiyoga 1-chome, Setagaya-ku, Tokyo; \\ *2 Tokyo Biochemical Research Institute: 41-8, Takada 3-chome, Toshima-ku, Tokyo)
}

\begin{abstract}
In vitro and in vivo formation of dimethylnitrosamine (DMNA) by bacteria isolated from human saliva were studied.

Six in 7 strains reduced nitrate to nitrite. Significant amount of DMNA was detected after $24 \mathrm{hr}$ incubation $\left(37^{\circ} \mathrm{C}\right)$ of bacteria in the medium containing sodium nitrate, dimethylamine hydrochloride (DMA $\cdot \mathrm{HCl})$, glucose and brain heart infusion. The highest concentration of DMNA was observed in the culture solution of Staphylococcus aureus, isolate A-1 and S. epidermidis, isolate $\mathrm{E}-2$, being $13.8 \mathrm{ppm}$ and $13.7 \mathrm{ppm}$, respectively. In the case of short term incubation $\left(37^{\circ} \mathrm{C}, 2 \mathrm{hr}\right)$ using $S$. epidermidis, isolate $\mathrm{E}-2, \mathrm{pH}$ lowered to 5.7 (initial $\mathrm{pH}$ was 6.5) and the concentration of nitrite increased to $310 \mathrm{ppm}$. When glucose was omitted from the incubation mixture, $\mathrm{pH}$ did not change, but the concentration of nitrite increased. The concentration of DMNA showed $16.7 \mathrm{ppm}$ after $2 \mathrm{hr}$ incubation with glucose and $0.3 \mathrm{ppm}$ without glucose.

In the animal experiments, DMNA was detected at the level of $0.2 \sim 1.9 \mu \mathrm{g} / \mathrm{animal}$ in the stomach contents of 5 in 8 guinea-pigs when cell suspension of $S$. epidermidis, isolate $\mathrm{E}-2$, sodium nitrate, $\mathrm{DMA} \cdot \mathrm{HCl}$ and glucose were orally administered.
\end{abstract}

\section{Introduction}

It is well known that the nitroso compounds have carcinogenicity towards specific target organs. Among them, dimethylnitrosamine (DMNA) has potent carcinogenicity, and has been shown to cause malignant tumors in liver, kidney and lung of the rat when given orally. Dimethylamine (DMA) which is one of the precursors of DMNA has been widely detected in seafoods, especially in sea fishes and fish roes. Kawamura et $a l .{ }^{1)}$ and Ito et al. ${ }^{2)}$ determined the amount of DMA in raw and roasted fishes, and many other kinds of foods. Nitrite, the other precursor, was widely destributed in natural products ${ }^{3)}$ such as vegetables and fruits, and also used as a color fixative in meat products or fish roes.

Moreover, the existence of nitrite in human saliva has been known. Tsujitsuka et al., ${ }^{4,5)}$ Okabe, ${ }^{8)}$ and Tannenbaum et $a l .{ }^{7), 8)}$ reported that salivary nitrite might be produced from nitrate by the action of microorganisms in oral cavity. These reports, however, did not clarify the relationship between the concentrations of nitrite and nitrate in saliva and those in the meal ingested. In the previous studies in this series, it was found that the concentrations of nitrate and nitrite in human saliva increased remarkably when sodium nitrate ${ }^{\text {) }}$ or some vegitables containing high amount of nitrate $^{\theta), 10)}$ were ingested, depending on the amount of nitrate ingested.

On the other hand, Sander, ${ }^{11)}$ Collines-

Table 1. Components of Growth Media

\begin{tabular}{lcc} 
& Medium I & Medium II \\
\hline $\mathrm{DMA} \mathrm{HCl}(\mathrm{g})$ & 0.5 & 0.5 \\
$\mathrm{NaNO}_{3}(\mathrm{~g})$ & 1.0 & 1.0 \\
Glucose $(\mathrm{g})$ & - & 2.0 \\
BHI $(\mathrm{g})$ & 3.7 & 3.7 \\
Water (ml) & 100 & 100 \\
& & $(\mathrm{pH} 7.0)$
\end{tabular}



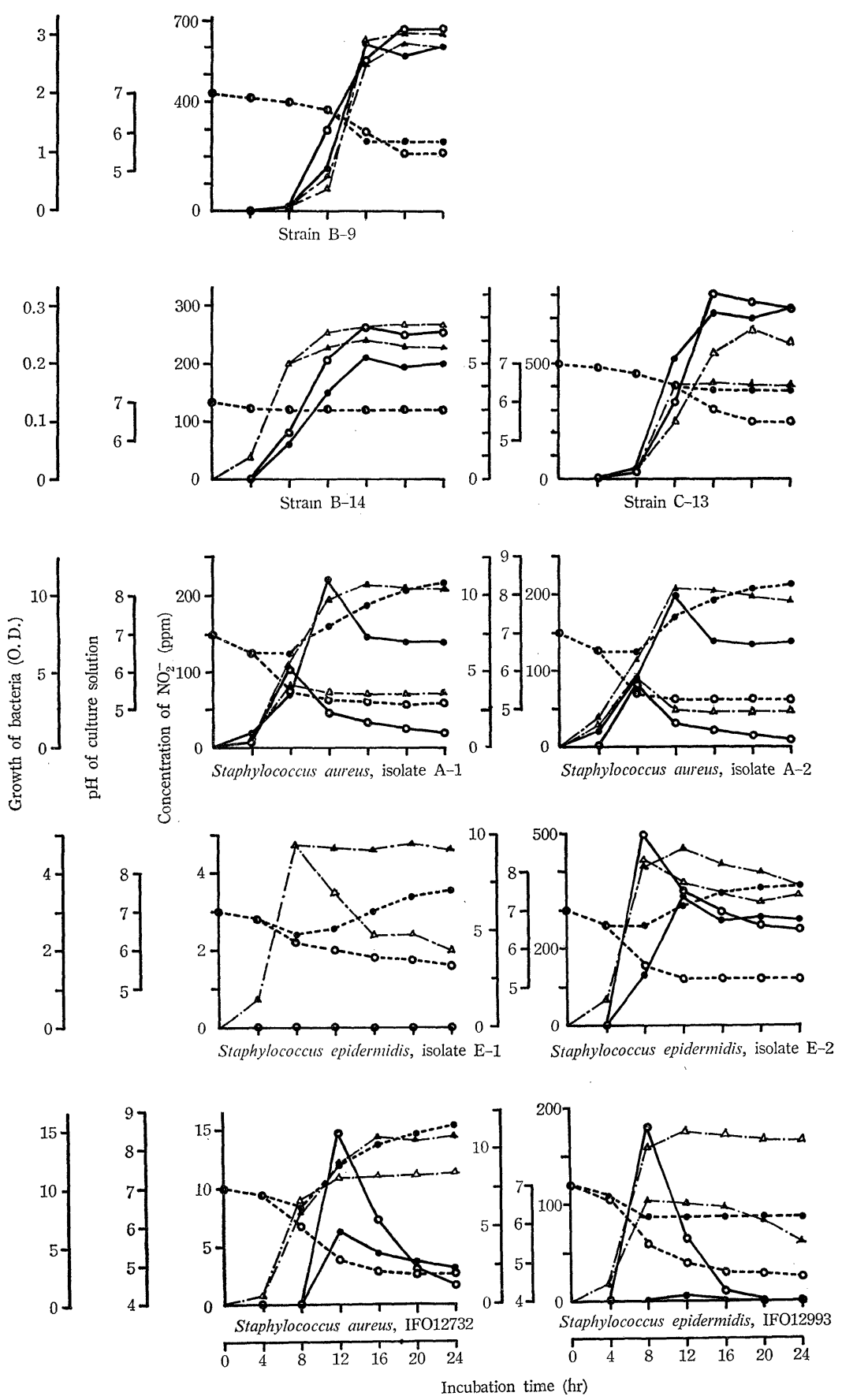

Fig. 1. Growth of bacteria, accumulation of nitrite and change of $\mathrm{pH}$ in the culture solution of bacteria isolated from human saliva

-. Medium I; O, Medium II; - - nitrite; ---, $\mathrm{pH}$; -.-, growth of bacteria. 
Thompson et al., ${ }^{12)}$ Howksworth et al., ${ }^{13)}$ Ayanaba et $a l .{ }^{14)}$ and Inoue $^{15)}$ reported that nitrosamines were formed from nitrite or nitrate and secondary or tertiary amines by various microorganisms. The present authors also observed the formation of DMNA in the incubated solution containing sodium nitrate, $\mathrm{DMA} \cdot \mathrm{HCl}$, glucose and brain heart infusion (BHI) when human saliva was added to the solution as the source of microorganisms. ${ }^{16)}$

In the present paper, 7 strains of bacteria were isolated from human saliva, and their abilities of nitrite and DMNA formation in vitro were compared. Furthermore, the formation of DMNA in the stomach of guineapig was tested by using S. epidermidis, one of the strains isolated.

\section{Experimental Methods}

\subsection{Growth media}

The components of growth media are shown in Table 1.

\subsection{Test organisms}

Staphylococcus aureus, isolate $\mathrm{A}-1, S$. aureus, isolate A-2, S. epidermidis, isolate E-1 and S. epidermidis, isolate E-2 and unidentified nitrate-reducing bacteria (strain $\mathrm{B}-9$, strain B-14 and strain C-13) were isolated from the saliva of one of the present authors (man, 31 years old). S. aureus IFO 12732 and S. epidermidis IFO 12993 were obtained from Institute for Fermentation, Osaka.

a) Isolation of Staphylococcus The sediment of human saliva was spread on mannitol salt agar (Eiken Chemical Co., Ltd.) plate, and incubated at $37^{\circ} \mathrm{C}$. Each 2 yellow and 2 white colonies were again spread on the agar plates. The selective culture was repeated several times for the isolation. The main properties of the yellow colonies were gramstain positive, cocci, coagurase positive, acid formation from mannitol positive, and $\mathrm{O} / \mathrm{F}$ test F-type. These properties coincided with those of S. aureus IFO 12732 and the description of S. aureus by Cowan et al. ${ }^{17)}$ The main properties of the white colonies were gramstain positive, cocci, coagurase negative, acid formation from mannitol negative, and $\mathrm{O} / \mathrm{F}$ test F-type. These properties coincided with those of S. epidermidis IFO 12993 and the description of $S$. epidermidis by Cowan et al. ${ }^{17)}$

b) Isolation of nitrate-reducing bacteria
The sediment of human saliva was spread on BHI (Difco Lab.) plates, and few colonies were spread on new BHI plate. The selective culture was repeated several times for the isolation. Three nitrate-reducing strains were selected from the colonies isolated. They were not identified enough, but strain B-9 was gramstain positive and rod-shaped; strain B-14 was gram-stain positive and rod-shaped; strain C13 was gram-stain positive and spherical.

\subsection{Formation of nitrite and DMNA in} vitro

a) Twenty-four hours incubation The test organisms were cultured in the media shown in Table 1 at $37^{\circ} \mathrm{C}$ with shaking. Growth of bacteria, $\mathrm{pH}$ and nitrite concentration in the culture solution were measured at definite intervals. DMNA was measured at $24 \mathrm{hr}$.

b) Two hours incubation The mixture of $20 \mathrm{ml}$ of cell suspension of $S$. epidermidis, isolate $\mathrm{E}-2$ in $3.7 \% \mathrm{BHI}$ solution $(1.8-2.8 \times$ $10^{\circ}$ cells $/ \mathrm{ml}$ ) and $2 \mathrm{ml}$ of the reagent solution containing $0.5 \mathrm{~g}$ of sodium nitrate, $0.25 \mathrm{~g}$ of $\mathrm{DMA} \cdot \mathrm{HCl}$ and $0.5 \mathrm{~g}$ of glucose was incubated at $37^{\circ} \mathrm{C}$. Nitrite concentration and $\mathrm{pH}$ were determined at definite intervals. DMNA was measured at $2 \mathrm{hr}$.

\subsection{Formation of DMNA in vivo}

The experiments were carried out according to the method of Inoue. ${ }^{15)}$

Ten $\mathrm{ml}$ of cell suspension of S. epidermidis, isolate $\mathrm{E}-2$ in $3.7 \% \mathrm{BHI}$ solution $(1.8-2.8 \times$ $10^{\circ}$ cells $/ \mathrm{ml}$ ) and $2 \mathrm{ml}$ of the reagent solution described above were given simultaneously by a stomach tube to the guinea-pig (Hartley, female, body weight $600 \sim 800 \mathrm{~g}$ ) which had been fasted from the day before. The stomach was exenterated after $2 \mathrm{hr}$, and the contents were collected. The stomach was washed with a small amount of water, and the washings were combined to the contents. Clear supernatant was obtained by centrifugation $(3000$ $\mathrm{rpm}, 10 \mathrm{~min})$. The precipitate was washed with a small amount of water and centrifuged. Both supernatants were combined and used for the sample solution for the determination of DMNA.

\subsection{Analytical procedures}

Nitrite was determined by the method described previously. ${ }^{10)}$ Growth of bacteria was measured at the wave length of $540 \mathrm{~nm}$ by a 
spectrophotometer. DMNA in the sample solution was extracted twice with three portions of dichloromethane. Dichloromethane layer was dried over night with anhydrous sodium sulfate, and concentrated to $0.1 \sim 1 \mathrm{ml}$. Detection and determination of DMNA were carried out by thin-layer chromatography and gas chromatography, respectively, under the conditions described previously. ${ }^{16)}$

3. Results and Discussion

3.1 Accumulation of nitrite by isolated bacteria

The accumulation curves of nitrite of 7 strains isolated from saliva and 2 strains obtained from IFO were shown in Fig. 1, together with the growth curves and the changes of $\mathrm{pH}$.

The accumulating patterns of nitrite were considerably different in the individual strains, but they were mostly classified to the following three types. (1) The concentration of nitrite increased with growth of bacteria and the maximum value was maintained up to 24 hr. Such a type was observed in three unidentified nitrate-reducing bacteria, strain B-9, strain B-14 and strain C-13. (2) The accumulation curve of nitrite had a sharp peak at $8 \sim$ $12 \mathrm{hr}$ and nitrite was almost completely lost at $24 \mathrm{hr}$. Two strains of Staphylococcus obtained from IFO belonged to this type. (3) The third was the intermediate type of the first two. S. aureus, isolate A-1 and A-2, and S. epidermidis, isolate E-2 corresponded to this type. In the case of $S$. epidermidis, isolate $\mathrm{E}-1$, nitrite was not detected in both medium $I$ and II, showing the lack of nitrate-reducing ability.

The changes of $\mathrm{pH}$ during the growth of bacteria were also different in the individual strains. When glucose was omitted from the medium, $\mathrm{pH}$ value first dropped and then gradually rose to about 8 at $24 \mathrm{hr}$, except three unidentified nitrate-reducing bacteria and $S$. epidermidis IFO 12993. However, when glucose was added, $\mathrm{pH}$ value lowered from the begining to reach about 5 at $24 \mathrm{hr}$, except strain B-14 which showed no $\mathrm{pH}$ change.

3.2 Accumulation of DMNA by isolated bacteria

The ammount of DMNA accumulated in the medium was determined after $24 \mathrm{hr}$ incubation. As shown in Table 2, the highest concentration of DMNA was detected in medium II of
Table 2. Concentration of DMNA in the Culture Solution after Incubation for $24 \mathrm{hr}$

\begin{tabular}{lcc} 
& Medium & $\begin{array}{c}\text { DMNA } \\
\text { (ppm) }\end{array}$ \\
\hline S. aureus, IFO 12732 & I & N.D. \\
& II & 7.2 \\
S. aureus, isolate A-1 & I & N.D. \\
& II & 13.8 \\
S. aureus, isolate A-2 & I & N.D. \\
& II & 9.0 \\
S. epidermidis, IFO 12993 & I & N.D. \\
& II & 11.8 \\
S. epidermidis, isolate E-1 & I & N.D. \\
& II & N.D. \\
S. epidermidis, isolate E-2 & I & 0.4 \\
& II & 13.7 \\
Strain B-9 & I & 3.9 \\
& II & 7.0 \\
Strain B-14 & I & 0.1 \\
& II & 0.1 \\
Strain C-13 & I & 0.5 \\
$\quad$ & II & 6.7 \\
$\quad$ & I & N.D. \\
& II & N.D.
\end{tabular}

S. aureus, isolate A-1 and S. epidermidis, isolate $\mathrm{E}-2$, being 13.8 and $13.7 \mathrm{ppm}$, respectively.

More acidification of the medium and more accumulation of DMNA were observed in medium II compared with medium I, except S. epidermidis, isolate $\mathrm{E}-1$ and strain $\mathrm{B}-14$. S. epidermidis, isolate $\mathrm{E}-1$ might have no nitrate reductase, so DMNA was not formed in spite of acidification of the medium. As the change of $\mathrm{pH}$ was not observed in medium I and II of strain B-14, the amount of DMNA accumulated was the same in both cases. In the medium without bacteria, the change of $\mathrm{pH}$ and the accumulations of nitrite and DMNA were not observed. This result shows that glucose does not directly participate to the formation of DMNA, but that it may accelate the formation of DMNA by acidifing the medium. It has been reported that the optimum $\mathrm{pH}$ of chemical formation of DMNA from nitrite and DMA is $3.3^{18)} \sim 3.4 . .^{18)}$

Tannenbaum et al. ${ }^{8)}$ reported that $S$. aureus and S. epidermidis isolated from human saliva have the ability of nitrite formation, and they discussed a possibility of formation of nitrosamines in mouth or stomach. However, the 
present authors examined the formation of DMNA when the reagent solution containing sodium nitrate, DMA $\cdot \mathrm{HCl}$, glucose and $\mathrm{BHI}$ were kept in human mouth for $15 \mathrm{~min}$, but DMNA was not detected in the spat out solution. ${ }^{16)}$ This fact seems to open another possibility of DMNA formation in the stomach.
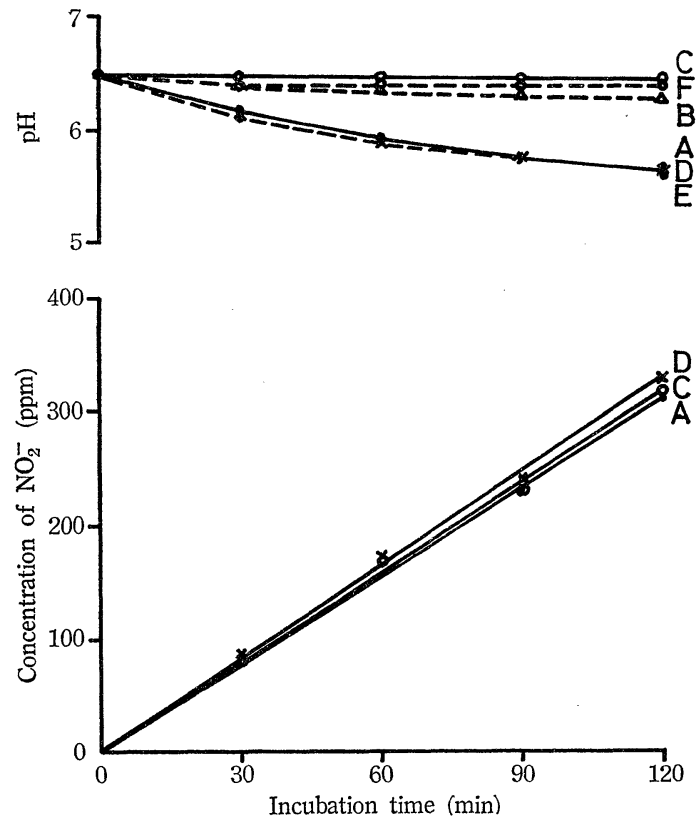

Fig. 2. Formation of nitrite and change of $\mathrm{pH}$ in the incubation mixture of S. epidermidis, isolate $\mathrm{E}-2$

$-\bullet, \mathrm{A} ; \triangle \cdots \triangle, \mathrm{B} ; \mathrm{O}-\mathrm{O}, \mathrm{C} ; \mathrm{X}-\mathrm{X}, \mathrm{D}$; $\times \cdots \times, \mathrm{E} ; \bigcirc \cdots \bigcirc, \mathrm{F}$.

Nitrite was not detected in incubation mixture $\mathrm{B}, \mathrm{E}$, and $\mathrm{F}$. The components of $\mathrm{A} \sim$ $\mathrm{F}$ were shown in Table 3.

\subsection{Formation of DMNA by short term incubation}

Before the experiment of DMNA formation in the guinea-pig stomach was started, in vitro formation of DMNA by S. epidermidis, isolate E-2 was carried out under the same condition as the in vivo experiment. Formation of nitrite and change of $\mathrm{pH}$ in the incubation mixtures shown in Table 3 were determined at definite intervals (Fig. 2). The amount of DMNA accumulated for $2 \mathrm{hr}$ was shown in Table 3.

In the complete incubation mixture, $\mathrm{pH}$ was acidified linearly to reach 5.7 at $2 \mathrm{hr}$, and the concentration of nitrite increased linearly to $310 \mathrm{ppm}$ (Fig. 2, curve A). The amount of DMNA was $16.7 \mathrm{ppm}$ at $2 \mathrm{hr}$ (Table 3). When glucose was omitted from the incubation mixture, no change of $\mathrm{pH}$ was observed regardless of the accumulation of $317 \mathrm{ppm}$ of nitrite (Fig. 2, curve C), and the accumulation of DMNA was only $0.3 \mathrm{ppm}$ (Table 3 ).

Inoue $^{15)}$ reported that a trace amount of DMNA was detected in $1 \mathrm{hr}$ incubation of the mixture of sodium nitrate, DMA $\cdot \mathrm{HCl}$ and the cell suspension of Escherichia coli (final $\mathrm{pH}$ 6.6), but that $0.56 \mathrm{mg}$ of DMNA was detected when glucose was added to the mixture (final pH 5.4 5.5). Our present result obtained by $S$. epidermidis was similar to the case of $E$. coli.

\subsection{Formation of DMNA in the stomach of guinea-pig}

DMNA in the stomach contents of guineapig was determined $2 \mathrm{hr}$ after the oral administration of cell suspension of S. epidermidis,

Table 3. Components of the Incubation Mixture and Formation of DMNA by $S$. epidermidis, isolate E-2

\begin{tabular}{|c|c|c|c|c|c|c|c|}
\hline Incubation mixture & & $\mathrm{A}$ & $\mathrm{B}^{\mathrm{b})}$ & $\mathrm{C}$ & $\mathrm{D}$ & $\mathrm{E}$ & $\mathrm{F}$ \\
\hline \multicolumn{2}{|l|}{ Cell suspension ${ }^{a)}(20 \mathrm{ml})$} & + & - & + & + & + & + \\
\hline \multirow{3}{*}{ Reagent solution $(2 \mathrm{ml})$} & $\mathrm{NaNO}_{3}(0.5 \mathrm{~g})$ & + & + & + & + & - & - \\
\hline & $\mathrm{DMA} \cdot \mathrm{HCl}(0.25 \mathrm{~g})$ & + & + & + & - & + & - \\
\hline & glucose $(0.5 \mathrm{~g})$ & + & + & - & + & + & - \\
\hline
\end{tabular}

Incubation at $37^{\circ} \mathrm{C}$ for $2 \mathrm{hr}$

DMNA (ppm)

16.7 N.D. $0.3 \quad$ N.D. N.D. N.D.

a) $1.8-2.8 \times 10^{9}$ cells $/ \mathrm{ml}$ of $3.7 \%$ BHI solution

b) Cell suspension was replaced with $3.7 \%$ BHI solution. 
Table 4. Formation of DMNA in Guinea-pig Stomach

\begin{tabular}{|c|c|c|c|c|}
\hline Group & No. & $\begin{array}{l}\text { Contents in } \\
\text { stomach (ml) }\end{array}$ & $\begin{array}{l}\mathrm{pH} \text { of the } \\
\text { contents }\end{array}$ & DMNA $(\mu \mathrm{g})$ \\
\hline \multirow{8}{*}{ A } & 1 & 24 & 6.0 & 0.3 \\
\hline & 2 & 15 & 4.9 & 0.6 \\
\hline & 3 & 18 & 4.0 & 0.2 \\
\hline & 4 & 20 & 6.3 & N.D. \\
\hline & 5 & 18 & 5.6 & N.D. \\
\hline & 6 & 7 & 6.9 & N.D. \\
\hline & 7 & 25 & 3.4 & 0.2 \\
\hline & 8 & 28 & 4.9 & 1.9 \\
\hline \multirow{4}{*}{ B } & 1 & 3 & 3.0 & N.D. \\
\hline & 2 & 8 & 1.7 & N.D. \\
\hline & 3 & 1 & 2.1 & N.D. \\
\hline & 4 & 9 & 1.7 & N.D. \\
\hline \multirow{3}{*}{$\mathrm{C}$} & 1 & 21 & 5.4 & N.D. \\
\hline & 2 & 13 & 6.6 & N.D. \\
\hline & 3 & 38 & 3.5 & N.D. \\
\hline \multirow{4}{*}{$\mathrm{D}$} & 1 & 33 & 4.2 & 0.6 \\
\hline & 2 & 23 & 3.0 & 0.5 \\
\hline & 3 & 11 & 6.9 & N.D. \\
\hline & 4 & 20 & 3.1 & 0.3 \\
\hline
\end{tabular}

Dose: Group A, cell suspension of $S$. epidermidis, isolate E-2 and reagent solution; Group B, reagent solution; Group C, cell suspension of $S$. epidermidis, isolate E-2; Group $\mathrm{D}$, cell suspension of $S$. epidermidis, isolate E-2 and reagent solution after the pretreatment with cell suspension of S. epidermidis, isolate $\mathrm{E}-2$ and $25 \%$ sodium nitrate solution on the day before

isolate $\mathrm{E}-2$ and the reagent solution containing sodium nitrate, $\mathrm{DMA} \cdot \mathrm{HCl}$ and glucose. $0.2 \sim 1.9 \mu \mathrm{g}$ of DMNA was detected on the 5 in 8 guinea-pigs (Table 4, group A). In the group $\mathrm{C}$ administered distilled water instead of the reagent solution, no DMNA was detected. In the group B administered 3.7\% BHI solution instead of the cell suspension, DMNA was not detected, the contents of stomach were only $1 \sim 9 \mathrm{ml}$ and $\mathrm{pH}$ was $1.7 \sim 3.0$, showing the normal function of stomach. On the other hand, in the case of the guinea-pig administered the cell suspension (group A, C and D), the contents of stomach were $7 \sim 33 \mathrm{ml}$ and $\mathrm{pH}$ was $3.1 \sim 6.9$, showing the abnormal function of stomach. In the group D which was administered $10 \mathrm{ml}$ of the cell suspension and $2 \mathrm{ml}$ of $25 \%$ sodium nitrate solution on the day before the experimental day, and which was further administered $10 \mathrm{ml}$ of the cell suspension and the reagent solution on the experimental day, according to the method of Inoue, ${ }^{15)}$ $0.3 \sim 0.6 \mu \mathrm{g}$ of DMNA was detected.
Inoue reported ${ }^{15)}$ that DMNA was not detected in the stomach of guinea-pig $1 \mathrm{hr}$ after the oral administration of sodium nitrate, glucose, $\mathrm{DMA} \cdot \mathrm{HCl}$ and cell suspension of $E$. coli, but that it was formed only when the animal had been administered with the cell suspension and sodium nitrate the day before of the experimental day in order to accumulate nitrite in the stomach. He also pointed out that such a pre-treatment caused the lowering of stomach function, accompanying the decrease of gastric juice and the stagnation of stomach contents.

However, in our present experiments, DMNA was significantly formed in the stomach of guinea-pig $2 \mathrm{hr}$ after the oral administration of the reagent solution and cell suspension of S. epidermidis, isolate E-2. This discrepancy suggests that our organisms have a strong ability of nitrate reduction and also caused the stomach function to lower immediately resulting in the increases of stomach contents and $\mathrm{pH}$ value. Such a state of stomach may bring about the favorable condition for the 
growth of bacteria and the formation of DMNA.

In the experiments of DMNA formation from sodium nitrite and $\mathrm{DMA} \cdot \mathrm{HCl}$, Sakai et $a l .{ }^{18)}$ demonstrated that the yield of DMNA was $10.75 \%$ in simulated gastric juice and only $0.09 \sim 1.10 \%$ in the stomach of rabbit. In the present experiments of DMNA formation from sodium nitrate and $\mathrm{DMA} \cdot \mathrm{HCl}$ by the action of bacteria, the amount of DMNA formed in the stomach of guinea-pig was also lower than that of in vitro experiment.

Staphylococcus is widely distributed in life environment, and isolated from skin and saliva of man or animals, air, sewerge, and almost every thing. ${ }^{20)}$ In the case of stomach cancer or gastritis, various microorganisms including Staphylococcus were detected in the stomach because of high $\mathrm{pH}$ of gastric juice. ${ }^{21)}{ }^{22)}$

In human saliva, however, the population of Staphylococcus is not so much and there are many other microorganisms which possess nitrate-reducing activity. In the present study of DMNA formation in the stomach of guineapig, only S. epidermidis, isolate E-2 was used, but the same phenomena may be expected in other nitrate-reducing bacteria.

Conclusively, there is a possibility of DMNA formation in the stomach by the combined action of nitrate, DMA and oral nitrate-reducing bacteria, if the stomach function is lowered to provide some favorable condition for DMNA formation.

\section{Acknowledgment}

The authors are indebted to Dr. I. Kawashiro, Director of National Institute of Hygienic Sciences, for his encouragement. This work was supported by Cancer Research Funds (1975) from the Ministry of Health and Welfare, Scientific Research Funds (1975) from the Ministry of Education, Science and Culture, and Special Research Funds (1975) from National Institute of Hygienic Sciences.

\section{References}

1) Kawamura, T., Sakai, K., Miyazawa, F., Wada H., Ito, Y., Tanimura, A.: J. Food Hyg. Soc., 12, 192 (1971).

2) Ito, Y., Sakuta, H., Takada, H., Tanimura, A.: ibid., 12, 404 (1971).

3) Harada, M., Nakamura, Y., Tanimura, A.: ibid., 13, 36 (1972).

4) Tsujitsuka, T.: Shigaku, 60, 222 (1972).

5) Tsuda, M., Tsujitsuka, T., Matsuo, T., Tomizuka, K.: ibid. 60, 232 (1972).

6) Okabe, S.: Hikone-ronso, No. 162, 163, p. 165 (1973).

7) Tannenbaum, S.R.: Note on Meeting of Joint FDA-USDA. Group on Nitrite-Nitrate and nitrosamine in Foods. Feb. 16, 1973.

8) Tannenbaum, S. R., Sinsky, A. J., Weisman, M., Bishop, W.: J. Nat. Cancer Inst., 53, 79 (1974).

9) Ishiwata, H., Boriboon, P., Nakamura, Y., Harada, M., Tanimura, A., Ishidate, M.: J. Food Hyg. Soc., 16, 19 (1975).

10) Harada, M., Ishiwata, H., Nakamura, Y., Tanimura, A., Ishidate, M.: ibid., 16, 11 (1975).

11) Sander, J.: Hoppe-Seyler's Z. Physiol. Chem., 349, 429 (1968).

12) Collins-Thompson, D.L., Sen, N.P., Asis, B., Schwinghamer, L.: Can. J. Microbiol., 18, 1968 (1972).

13) Howksworth, G., Hill, M.J.: Biochem. J., 122, $28 \mathrm{p}$ (1971).

14) Ayanaba, A., Alexander, M.: Appl. Microbiol., 25, 862 (1973).

15) Inoue, Y.: Hiroshima Daigaku Igaku Zasshi, 20, 357 (1972).

16) Ishiwata, H., Tanimura, A., Ishidate, M.: J. Food Hyg. Soc., 16, 234 (1975).

17) Cowan, S.T., Steel, K.J. (translated by Sakazaki, T., Shimazaki, Y.) "Manual for the Identification of medical Bacteria" p. 80 (1967) Naya Shoten.

18) Sakai, A., Tanimura, A.: J. Food Hyg. Soc., 12,170 (1971).

19) Mirvish, S.: J. Nat. Cancer Inst., 44, 633 (1970).

20) Fukumi, H., Ushida, D., Mitsuhashi, S., Yamamoto, T., "Medical Microbiology" p. 483 (Igaku shoin, 1960).

21) Oshio, S.: J. Keio Med. Soc., 37, 2635 (1960).

22) Sugiyama, T., Ogasawara, T., Kobari, S., Yusa, Y.: Tohoku Igaku Zasshi, 52, 355 (1955). 